\title{
Effect of lithium nitrate on the reaction between opal aggregate and sodium and potassium hydroxides in concrete over a long period of time
}

\author{
J. ZAPAŁA-SŁAWETA* and Z. OWSIAK \\ Kielce University of Technology
}

\begin{abstract}
Alkali-silica reaction (ASR) is a reaction between amorphous or poorly crystallized siliceous phase, present in aggregates, and sodium and potassium hydroxides in the pore solution of concrete. Chemical admixtures such as lithium compounds are known to have high potential of inhibiting ASR. The aim of this study was to determine the effect of lithium nitrate on ASR in mortars containing high reactive opal aggregate over a long period of time. Mortar bar expansion tests were performed and microstructures of mortar bars were observed by scanning electron microscopy coupled with an energy dispersive X-ray microanalyser. Results from this study showed that effectiveness of lithium nitrate in mitigating ASR was limited over a long period of time. A larger amount of ASR gel which was formed in the presence of lithium nitrate indicated that the deterioration processes intensify within longer periods of time, which so far has not been observed in literature. Microscopic observation confirmed the presence of alkali-silica gel and delayed ettringite in mortars with lithium nitrate.
\end{abstract}

Key words: alkali-silica reaction, lithium nitrate, ettringite formation, expansion, SEM/EDS.

\section{Introduction}

The expansive reaction that occurs between alkali hydroxides and reactive aggregate leads to degradation in the form of volume increase and subsequent cracking of concrete. Differences in the mineral composition of constituent aggregates make it difficult to find effective ways of reducing the reaction effects. Another difficulty stems from different reaction rates of aggregate rocks [1]. The effects of the reaction between aggregates and $\mathrm{Na}^{+}$and $\mathrm{K}^{+}$ions can be greatly reduced by pozzolanic and hydraulic additions or some chemical admixtures, as actively investigated and reported in Polish specialist literature. Examples include the attempts to determine the application potential of lime fly ash and natural pozzolans for mitigating the negative effects of internal corrosion in concrete [2-4], or the use of lithium compounds [5].

The effectiveness of lithium ions in reducing the effects of sodium and potassium hydroxides reaction with reactive aggregates depends on the type of lithium compound, the molar ratio of lithium to sodium and potassium ([Li]/[Na $+\mathrm{K}])$, the amount of alkali in cement $\left(\mathrm{Na}_{2} \mathrm{O}_{\mathrm{e}}\right)$ and the reactivity of aggregates used [6-8]. Maintaining the molar ratio $[\mathrm{Li}] /[\mathrm{Na}+\mathrm{K}]$ between 0.6 and 1.2 is sufficient for most lithium compounds to limit the adverse effect of reactive aggregate on concrete durability $[9,10]$.

Lithium nitrate is considered to be an inhibitor of the alkali-aggregate reaction [11]. The exact mechanism by which lithium ions exert this effect remains unclear. Various hypoth-

*e-mail: jzapala@tu.kielce.pl

Manuscript submitted 2017-09-06, revised 2017-10-16, initially accepted for publication 2017-10-30, published in December 2017. eses have been put forward to explain the role of lithium ions in the reaction. These include, but are not limited to, a hypothesis of reduced silica reactivity caused by the formation of a layer of lithium silicate crystallites or lithium ion-rich amorphous products on the silica surface. This layer on the surface of the aggregate prevents the reaction of silica with sodium and potassium hydroxides $[12,13]$. Recent years have brought more reports on the modified composition and properties of sodium-potassium-calcium silicate gels with lithium ions. Sodium and potassium ions in gels are exchanged for lithium ions, which makes them less swellable [14, 15]. Gels with lithium ions are more compact, which limits the diffusion of hydroxyl, sodium and potassium ions into reactive grains [16].

Studies of the alkali-aggregate reaction have often indicated the presence of delayed ettringite [17, 18]. The coexistence of aggregate reaction products with ettringite has been widely observed, especially in concrete railway sleepers in Finland, Sweden, Australia, Germany, South Africa, United States and China [19-23]. According to the current state of knowledge, the delayed ettringite crystallizes in the microcracks generated by the aggregate reaction with sodium and potassium hydroxides, but is not the primary source of the cracks [24, 25]. Ettringite is not produced in strongly alkaline environments. However, when the concentration of sodium and potassium hydroxides decreases as a result of reacting with reactive aggregates, the conditions for its crystallization become favourable [26, 27].

Data on the simultaneous effects of lithium ions on alkaline corrosion and on delayed ettringite formation in lithium nitrate mortars are sporadic in the literature. Ekolu et al. investigated the expansion of mortars heat-cured at $95^{\circ} \mathrm{C}$ and then stored for 12 months in lime water at room temperature [28]. They found that lithium nitrate was able to effectively inhibit the 
aggregate reaction with sodium and potassium hydroxides in addition to reducing delayed ettringite formation. Electrochemical incorporation of lithium ions into the cores drilled from railroad concrete sleepers, cracked due to the alkali-aggregate reaction and delayed ettringite formation, was also effective. No ettringite was found in the microstructure of the mortars [29].

This paper discusses the results of investigations of mortars with higher alkali content and with reactive opal aggregate, to which lithium nitrate was added as a corrosion inhibitor. Reports on the effects of lithium nitrate admixture on the alkali-aggregate reaction over long periods of time are scarce. Another aim of this study was also to investigate whether the formation of delayed ettringite occurs in lithium nitrate mortars not subjected to steam curing, as observed in mortars containing opal aggregates without lithium ions [27]. Mortar expansions were observed for three years of hardening at $38^{\circ} \mathrm{C}$ and at relative humidity $>95 \%$. Microstructure of the mortar was examined by means of scanning electron microscopy to determine the distribution and morphology of the aggregate-sodium and potassium reaction products and the presence of ettringite.

\section{Materials and methods}

The mortars were produced with Portland cement CEM I 42.5 R, with constituents as in Table 1.

Alkali content in cement was increased to $1.1 \%$ by adding a relevant amount of $\mathrm{K}_{2} \mathrm{SO}_{4}$ to the mixing water. Non-reactive quartz sand and highly reactive opal aggregate (opal-CT) with a particle size of $0.5-1 \mathrm{~mm}$, constituting a $6 \%$ aggregate mass, were used as aggregates. The mortars were made in accordance with the requirements set out in ASTM C227 [30]. The "aggregate to cement" mass ratio was 2.25 , and the water-cement ratio was 0.47 .

Lithium nitrate was added along with the mixing water in the amount corresponding to the molar ratio of lithium ions to alkali in cement, i.e. 1.0 .

Five $25 \times 25 \times 250 \mathrm{~mm}$ bars were moulded from both mortar types - with and without lithium nitrate. The mortar specimens were stored over water at $20 \pm 2^{\circ} \mathrm{C}$.

After $24 \mathrm{~h}$, the bars were placed in polyethylene containers at $38 \pm 2{ }^{\circ} \mathrm{C}$ at the relative humidity $>95 \%$.

The Graf-Kaufman apparatus measured the change in length of the bars after demoulding, first as the so-called zero measurement, then every 30 days up to 540 days. In order to investigate progress of the alkali-aggregate reaction, the mortars were stored under predetermined conditions for a period of 1080 days, and the linear expansion of the specimens was measured every 180 days.

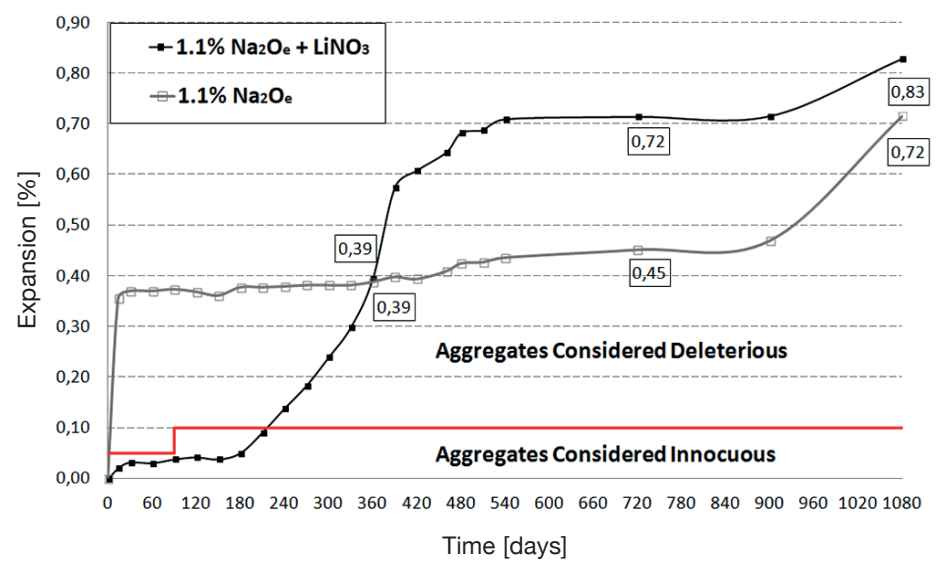

Fig. 1. Mortar bar expansion determined as per ASTM C227

\section{Test results}

3.1. Mortar expansion. Figure 1 shows the expansion data of the mortars with and without lithium nitrate. The ranges of allowable expansion of the specimens are marked by a red line. The expansions of mortar bars exceeded $0.05 \%$ up to 90 days and $0.10 \%$ after 90 days, which indicates that the aggregate has a potential to react with sodium and potassium hydroxides.

The expansion of lithium nitrate-free mortar increased significantly in the early days, exceeding the allowable standard values of linear expansion at 15 days of moulding the specimens. The length expansions over longer periods of time grew only slightly, reaching a value of $0.45 \%$ at 720 days, and then increasing rapidly after 900 days.

The expansion of lithium nitrate mortar had a different course. Up to 180 days of reaction, the allowable expansion was not exceeded. After 180 days, there was a significant increase in expansion, which only stabilized at 540 days, to increase again at 900 days. At 1080 days, it was $0.83 \%$, i.e. $15.3 \%$ higher than the expansion of the mortar without lithium nitrate.

Observations of the surface of the mortars proves the formation of white silica gel exudations, visible in larger amounts in lithium nitrate mortars (Fig. 2 a-b).

3.4. Mortar microstructure. In the microstructure of the mortar without lithium nitrate, a gel of calcium-potassium blade-shaped silicate was observed, mainly on the surface of the reactive aggregate and in the air voids (Fig. 3a). The gel contained significant amounts of calcium (Fig. 3b), which may suggest its low swelling capacity. This is due to the exchange of sodium and potassium ions in calcium silicate gels with calcium ions during the reaction. Well-crystallized ettringite

Table 1

Cement chemical composition [\%]

\begin{tabular}{|c|c|c|c|c|c|c|c|c|c|c|c|}
\hline Material & $\mathrm{SiO}_{\mathbf{2}}$ & $\mathrm{Al}_{\mathbf{2}} \mathrm{O}_{\mathbf{3}}$ & $\mathrm{Fe}_{\mathbf{2}} \mathrm{O}_{\mathbf{3}}$ & $\mathbf{C a O}$ & $\mathbf{M g O}$ & $\mathbf{S O}_{\mathbf{3}}$ & $\mathrm{K}_{\mathbf{2}} \mathrm{O}$ & $\mathrm{Na}_{\mathbf{2}} \mathrm{O}$ & $\mathrm{TiO}_{\mathbf{2}}$ & $\mathrm{LOI}^{*}$ & $\mathbf{N . s . p .}^{* *}$ \\
\hline Cement & 20.20 & 4.80 & 3.00 & 61.70 & 1.80 & 2.70 & 0.78 & 0.15 & 0.45 & 3.00 & 1.00 \\
\hline
\end{tabular}

${ }^{*}$ LOI - loss of ignition $\quad{ }^{* *}$ N.s.p - parts non-soluble in $\mathrm{HC} 1$ and $\mathrm{Na}_{2} \mathrm{CO}_{3}$ 

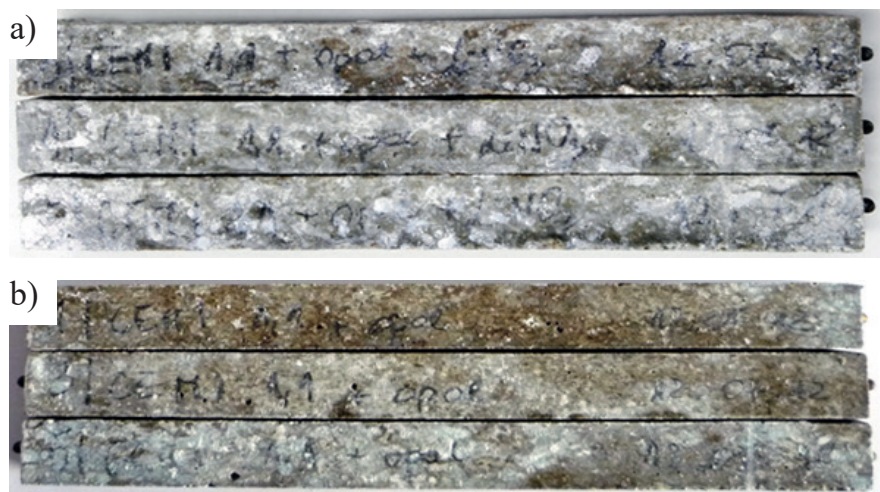

Fig. 2. Mortar specimens at 1080 days: a) with lithium nitrate, b) without lithium nitrate

a)

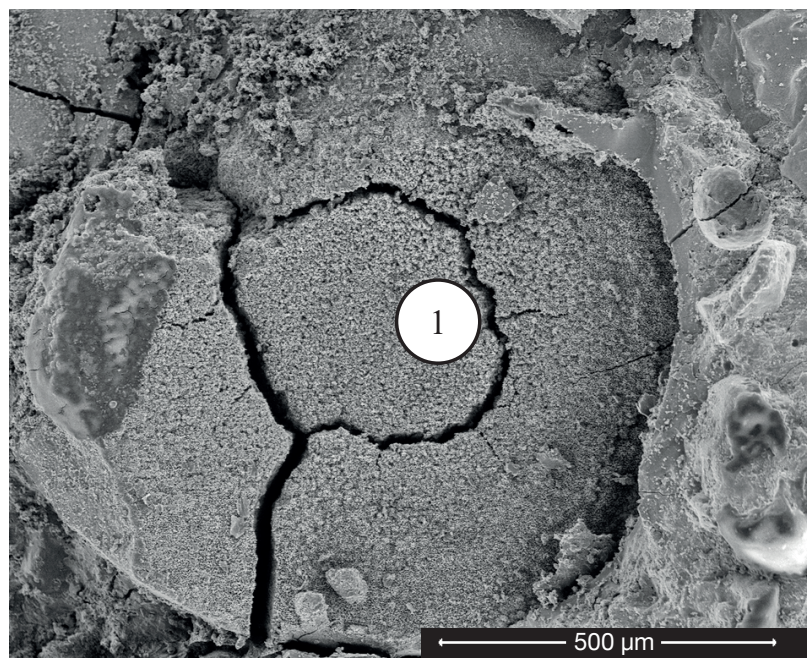

b)

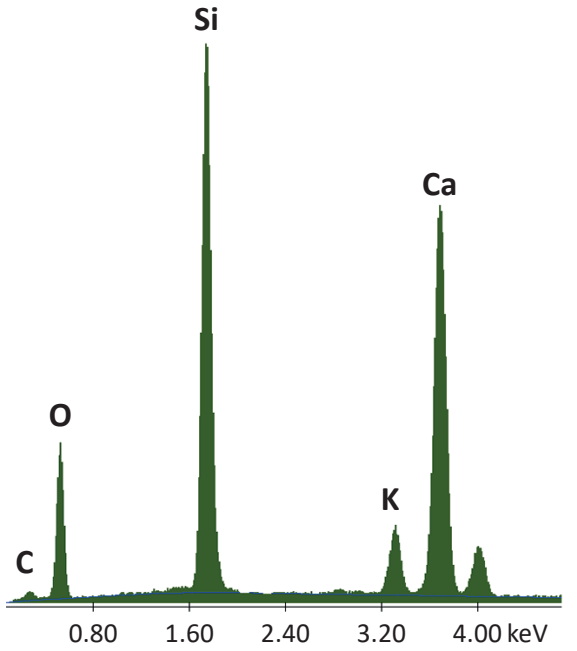

Fig. 3. a) calcium-potassium silicate gel in place of an opal grain in the mortar without lithium nitrate, b) gel composition

(Fig. $4 \mathrm{a}-\mathrm{c}$ ) was found in the resulting cracks, in the pores and some of the cement paste-aggregate transition zones.

Microstructure of lithium nitrate mortars after 1080 days of hardening showed the presence of potassium silicate gels, mainly around opal grains, in air voids and in the matrix of the cement a)

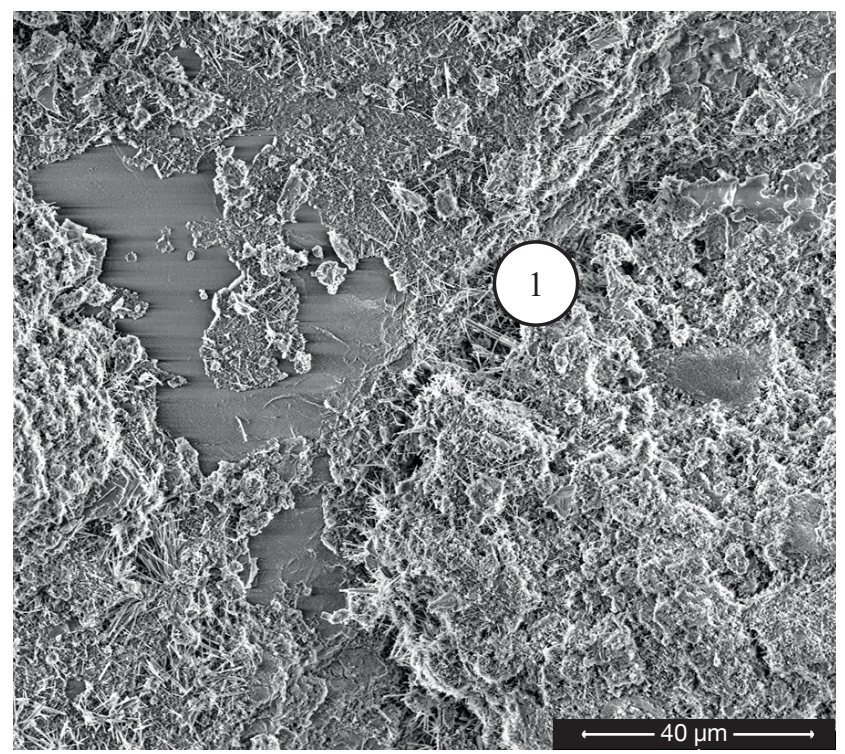

b)

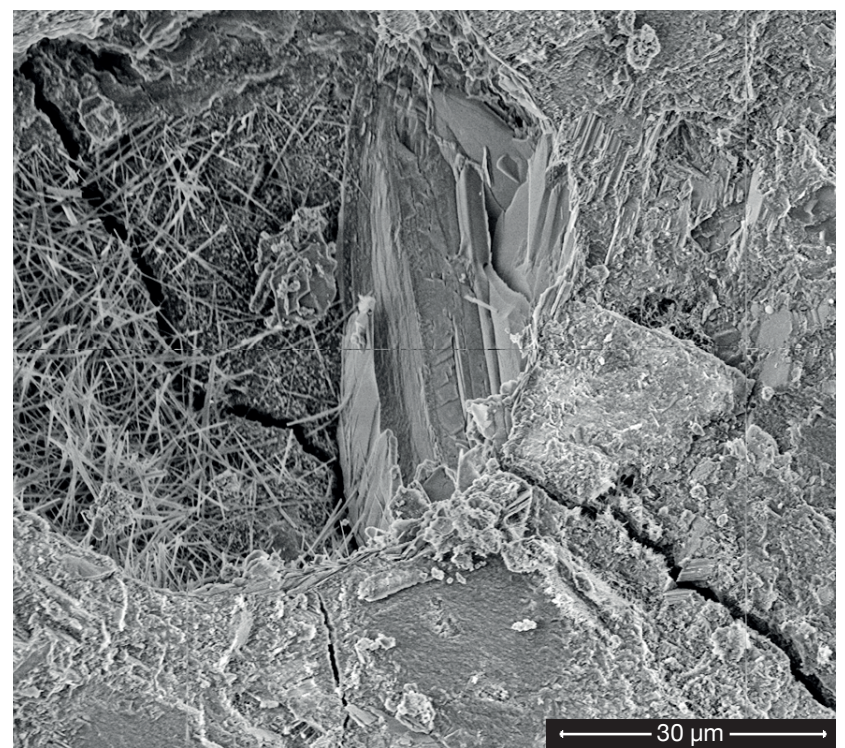

c)

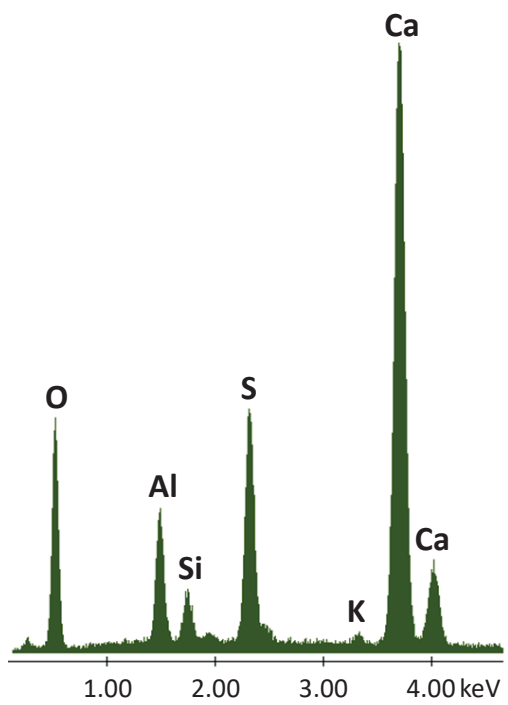

Fig. 4. Ettringite formation in mortar without lithium nitrate: a) in a crack, b) in air void, c) microanalysis at point 1 
paste. The reaction products were mainly amorphous (Fig 5a, 6a) and rich in potassium (Fig. 5b, 6c). Reaction products formed also at the site of opal aggregate grains in the crystalline form, as in the mortars without lithium nitrate. Needle-like crystals of ettringite were observed in the air voids, cracks and sometimes in the aggregate-paste transition zone (Fig. 6b, d). a)

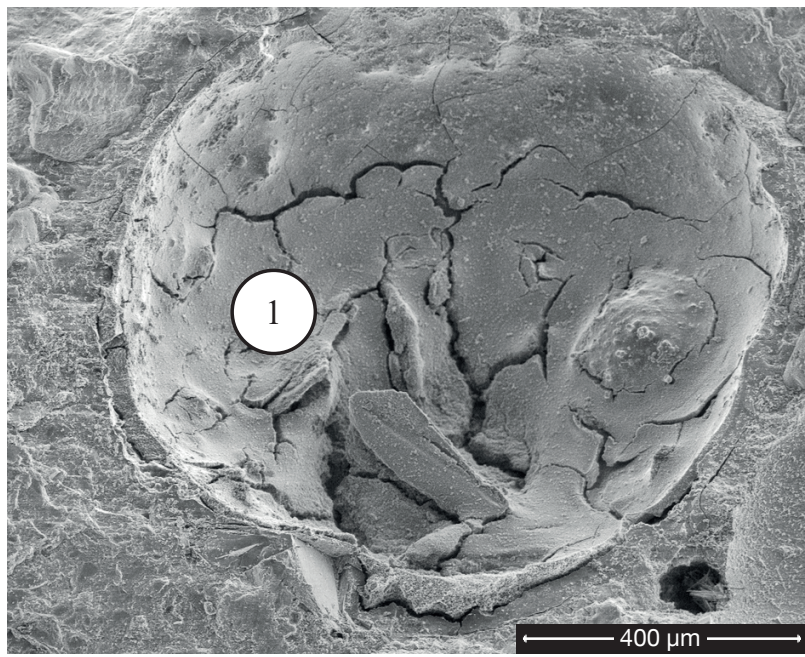

b)

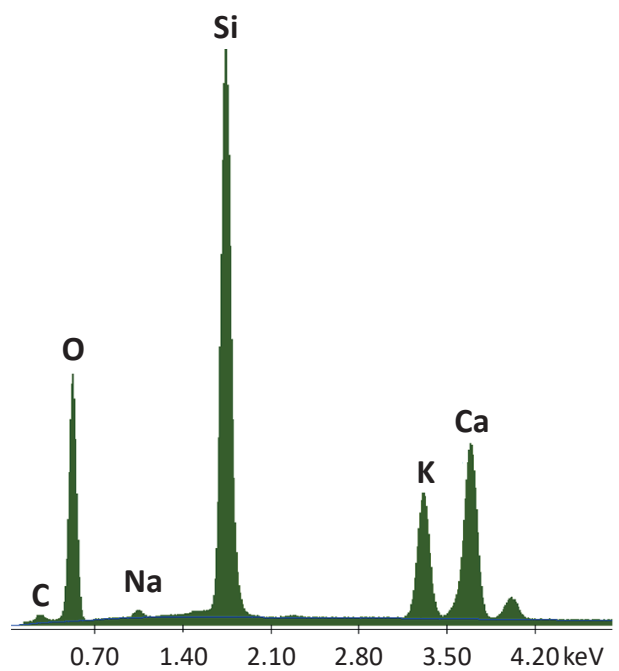

Fig. 5. a) massive calcium-potassium silicate gel in lithium nitrate mortar b) microanalysis at point 1

a)

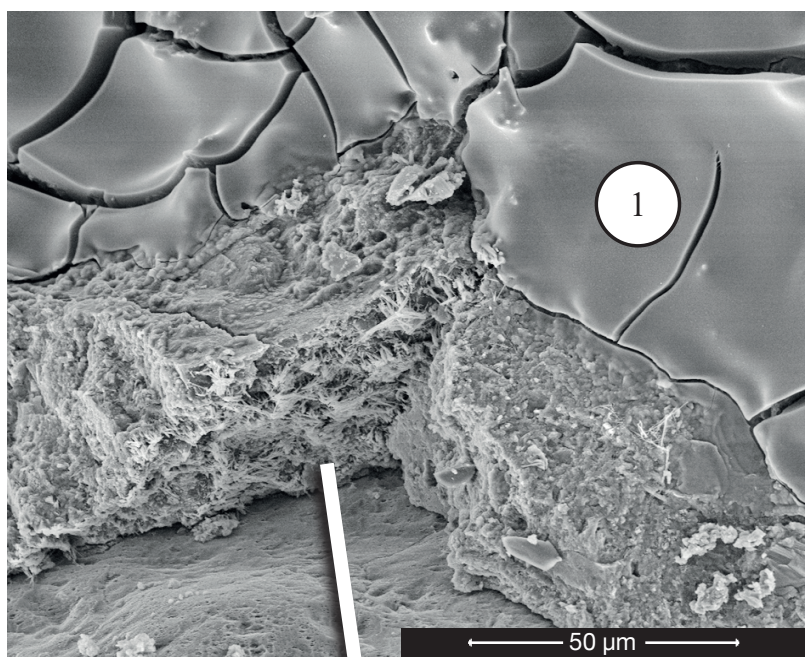

b)

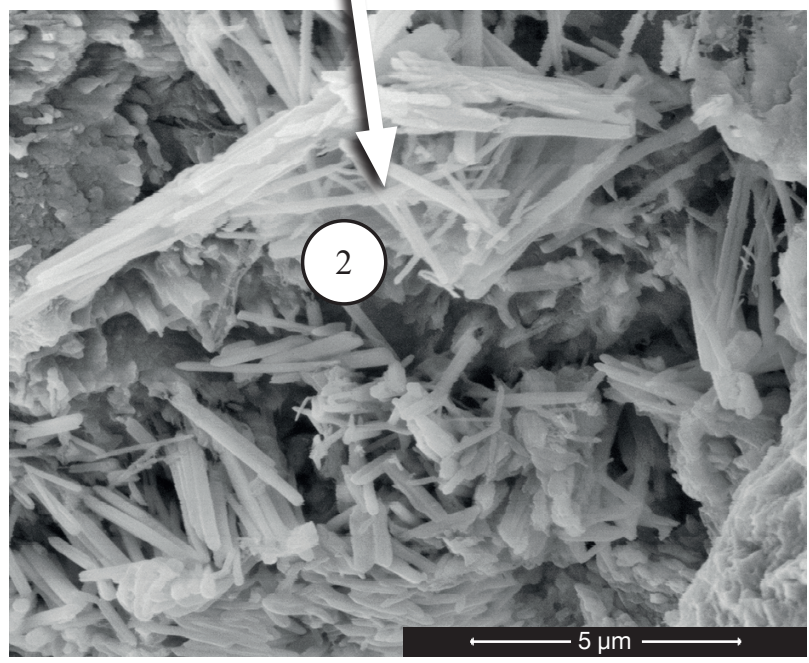

c)

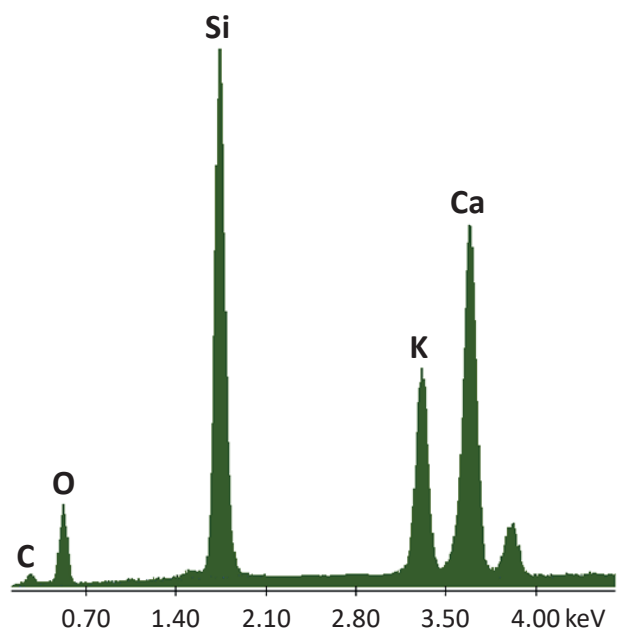

d)

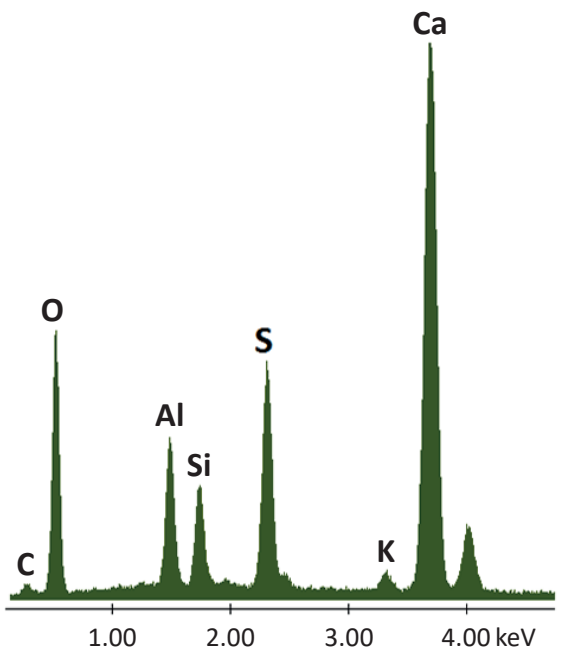

Fig. 6. a-b) ettringite in the paste-aggregate transition zone and visible calcium silica gel in lithium nitrate mortar, c-d) microanalysis at points 1 and 2 


\section{Discussion}

The examinations show that lithium nitrate did not reduce the expansion of mortars with reactive opal aggregate, which in the long term would put the stability of concrete at risk. Significant reduction in the expansion of lithium nitrate mortar with respect to specimens without lithium was observed up to 180 days of reaction. However, after 180 days, expansion increased considerably, reaching the magnitude comparable to that of lithium-free mortars at 360 days. Limiting expansion by lithium nitrate only at initial reaction times was observed in mortars with less lithium ions incorporated at a molar ratio of $[\mathrm{Li}] /[\mathrm{Na}+\mathrm{K}]=0.74$, but stored under conditions favouring a rapid alkali-aggregate reaction [31]. Mortar expansion at 360 days equalled that exhibited by the mortar without admixture, and at 720 days the expansion of the specimens with lithium was $60 \%$ higher. In the period from 900 to 1080 days expansion still grew but after 1080 days the differences in mortars elongation between samples with and without lithium nitrate were smaller.

Significant amounts of both amorphous and crystalline potassium-calcium silicate gels were observed in the microstructure of the mortars [5], which clearly reflects the large expansion of the bars. White exudations of alkali silicate gels on the surface of mortars were more abundant in the lithium nitrate mortar, where increased formation of reactive aggregate corrosion products occurred. Observation of the gels in the air voids and on mortar surfaces indicates their lower viscosity, as also observed by Afshinnia in mortars with ground clay bricks used as a potential inhibitor of corrosion processes [32]. Indeed, it is possible that a large quantity of gels, even with a lower swelling capacity, causes a significant expansion of mortars [33]. This problem requires further research to determine viscosity of the resulting gels and the swelling pressures generated by them.

After the stabilization period of 900 days, the expansion of mortars without lithium nitrate and those with lithium nitrate increased again. It is possible that the shape of the expansion curve is not only indicative of an alkali-aggregate reaction but also of the increase in the expansion caused by delayed ettringite formation [34]. Well-crystallized ettringite was found, in addition to hydrated potassium-calcium silicate, in some paste-aggregate transition zone, in the cracks and in the air voids. However, the agglomerates of ettringite were not as numerous as in the case of mortars with opal aggregate [18]. The presence of ettringite filling the voids in the aggregate-paste transition zone is a characteristic feature of mortars that exhibit expansion due to delayed ettringite formation [35].

The formation of delayed ettringite may therefore be the cause of the re-expansion recorded at 900 days in mortars both with and without lithium nitrate. The washout of sodium and potassium hydroxides from the cement mortar contributes to the formation of ettringite, increasing the release of sulphate ions from the C-S-H phase [36]. It is likely that the decrease in potassium and sodium concentration in the pore solution due to the increased gel formation and the microcracks resulting from the reactivity of the aggregate favour the recrystallization of ettringite. This confirms the earlier theory that the alkali-ag- gregate reaction is accompanied by the formation of ettringite [18]. It should also be noted that the total content of $\mathrm{SO}_{3}$ in the composite, being the sum of the $\mathrm{SO}_{3}$ content of the cement and the potassium sulphate addition, was $3.26 \%$. The sulphate content of $4 \%$ or less is considered to be low and insufficient even to bind aluminates and ferrites in the cement into monosulphate [37]. A small amount of ettringite can, however, be detected in concrete even after several years.

\section{Conclusions}

The results of this study have shown that:

- the addition of lithium nitrate to mortars was found to threaten their durability. Lithium nitrate used at the molar ratio of $[\mathrm{Li}] /[\mathrm{Na}+\mathrm{K}]$ at the level of 1.0 did not reduce the effects of alkali-silica reaction over a long period of time. High bar elongation occurred from 180 to 540 days, indicating an advanced reaction between the opal aggregates and sodium and potassium hydroxides. The reason for the large and rapid expansion of the lithium nitrate mortar, observed up to 540 days of hardening, is the problem that needs further investigation.

- increased formation of a strongly hydrated alkali silica gel, located in the air voids, on the surface of opal aggregate and manifesting itself as multiple exudations on the specimen surface was observed in the specimens with lithium nitrate. The reaction products most probably had lower viscosity.

- microstructural observations of the bars containing lithium nitrate showed the presence of delayed ettringite mostly in large pores, cracks and sometimes in the aggregate-paste transition zone. It is possible that bars expansion after 900 days was caused by DEF formation. Nevertheless, further investigations into this matter are necessary.

\section{REFERENCES}

[1] Z. Owsiak, J. Zapała-Sławeta, and P. Czapik, "Diagnosis of concrete structures distress due to alkali-aggregate reaction", Bull. Pol. Ac.: Tech. 63 (1), 23-29 (2015).

[2] Z. Owsiak and P. Czapik, "Interfacial transition zone of cement paste-reactive aggregate in cement-zeolite mortars", Bull. Pol. Ac.: Tech. 63(1), 31-34 (2015).

[3] W. Drożdż and Z. Giergiczny, "Badanie reakcji alkalicznej ASR w betonie z cementów zawierających popiół lotny wapienny”, Corros. Prot. 6, 216-219 (2014).

[4] Z. Owsiak and A. Mazur, "Effect of chalcedony dust on ASR in mortars of reactive aggregate", Procedia Eng. 108, 475-480 (2015).

[5] J. Zapała-Sławeta, "The influence of lithium compounds on alkali-aggregate reaction in concrete", $P h D$ thesis, Kielce University of Technology, Kielce, 2015.

[6] B. Durand, "More results about the use of lithium salts and mineral admixtures to inhibit ASR in concrete", Proc. 11th ICAAR, Quebec, Canada, 623-632 (2000).

[7] J. Zapała-Sławeta and Z. Owsiak, "The role of lithium compounds in mitigating alkali-gravel aggregate reaction", Constr. Build. Mater. 115, 299-303 (2016). 
[8] X. Feng, M.D.A. Thomas, T.W. Bremner, B.J. Balcom, and K.J. Folliard, "Studies on lithium salts to mitigate ASR-induced expansion in new concrete: a critical review", Cem. Concr. Res. 35 (9), 1789-1796 (2005)

[9] C.L. Collins, J.H. Ideker, G.S. Willis, and K.E. Kurtis, "Examination of the effects of $\mathrm{LiOH}, \mathrm{LiCl}$, and $\mathrm{LiNO}_{3}$ on alkali-silica reaction", Cem. Concr. Res. 34, 1403-1415 (2004).

[10] M.S. Islam, "Performance of Nevada's aggregate on alkali-aggregate reactivity of in Portland cement concrete" UNLV Theses, Dissertations, Professional Papers, and Capstones, University of Nevada, Las Vegas, 243, 2010.

[11] W.J. McCoy and A.G. Caldwell, "New approach in inhibiting alkali-aggregate expansion", ACI Mater. J. 22 (9), 693-706 (1951).

[12] X. Feng, "Effects and mechanism of lithium nitrate on controlling alkali-silica reaction", University of New Brunswick, Canada, 2008.

[13] C. Tremblay, M.A. Bérubé, B. Fournier, M.D. Thomas, K.J. Folliard, and P.C. Nkinamubanz, "Use of the accelerated mortar bar test to evaluate the effectiveness of $\mathrm{LiNO}_{3}$ against alkali-silica reaction - Part 2: Comparison with results from the concrete prism test", J. ASTM Int. 5 (8), 1-21 (2008).

[14] X. Mo and B. Fournier, "Investigation of structural properties associated with alkali-silica reaction by means of macro- and micro-structural analysis", Mater. Charact. 58, 179-189 (2007).

[15] Z. Owsiak and J. Zapała-Sławeta, "The lithium nitrate effect on the concrete expansion caused by alkali-silica reaction in concrete of gravel aggregate", Cement Lime Concrete 20 (1), 25-31 (2015).

[16] A. Leemann, L. Lörtscher, L. Bernard, G.Le Saout, B. Lothenbach, and R.M. Espinosa-Marzal, "Mitigation of ASR by the use of $\mathrm{LiNO}_{3}-$ Characterization of the reaction products", Cem. Concr. Res. 59, 73-86 (2014).

[17] H. Bouzabata, S. Multon, A. Sellier, and H. Houari, "Swellings due to alkali-silica reaction and delayed ettringite formation: Characterisation of expansion isotropy and effect of moisture conditions", Cem. Concr. Compos. 34, 349-356 (2012).

[18] Z. Owsiak, "The effect of delayed ettriringite formation and alkali-silica reaction on concrete microstructure". Ceram.-Silik. 54(3) 277-283 (2010).

[19] A. Shayan and G.W. Quick, "Alkali-aggregate reaction in concrete railway sleepers from Finland", Proc. 16th ICMA, Duncanville, Texas, 69-79 (1994).

[20] R.E. Oberholster, H. Maree, and J.H.B. Brand, "Cracked Prestressed Concrete Railway Sleepers: Alkali-Silica Reaction or Delayed Ettringite Formation", Proc. 9th ICAAR, London, UK, 739-749 (1992).

[21] A. Shayan and G.W. Quick, "Microscopic features of cracked and uncracked concrete railway sleepers", ACI Mater. J. 89 (4), 348-361 (1992).
[22] S. Sahu and N. Thaulow, "Delayed ettringite formation in Swedish concrete railroad ties", Cem. Concr. Res. 34 (9), 1675-1681 (2004).

[23] K. Maa, G. Longa, and Y. Xie, "A real case of steam-cured concrete track slab premature deterioration due to ASR and DEF", Case Stud. Constr. Mater. 6, 63-71 (2017).

[24] S. Diamond and S. Ong, "Combined effects of alkali silica reaction and secondary ettringite deposition in steam cured mortars", Ceram. Trans. 40, 79-90 (1994).

[25] Z. Owsiak, "Alkali-aggregate reaction in concrete containing high-alkali cement and granite aggregate", Cem. Concr. Res. 34, 7-11 (2004).

[26] P.W. Brown and J.V. Bothe, "The stability of ettringite", Adv. Cem. Res. 5 (18), 47-63 (1993)

[27] Z. Owsiak, "The importance of ettringite accompanying the alkali-aggregate reaction in several-year-old mortars", Cement Lime Concrete 74, 40-46 (2007).

[28] S.O. Ekolu, M.D.A. Thomas, and R.D. Hooton, "Dual effectiveness of lithium salt in controlling both delayed ettringite formation and ASR in concretes", Cem. Concr. Res. 37, 942-947 (2007).

[29] A. Santos Silva, M. Salta, M.E. Melo Jorge, M.P. Rodrigues, and A.F. Cristino, "Research on the suppression expansion due to ASR. Effect of coatings and lithium nitrate", Proc. 13th ICAAR, Trondheim, Norway, 1250-1259, (2008).

[30] ASTM C 227 - 10 Standard Test Method for Potential Alkali Reactivity of Cement - Aggregate Combinations (Mortar-Bar Method).

[31] Z. Owsiak and J. Zapała-Sławeta, "The effect of lithium nitrate on the alkaline reactivity of opal", Proc. $10^{\text {th }}$ TRANSCOM, Zilina, Slovak Republic, 233-236 (2013).

[32] K. Afshinnia and A. Poursaee, "The potential of ground clay brick to mitigate Alkali-Silica Reaction in mortar prepared with highly reactive aggregate", Constr. Build. Mater. 95, 164-170 (2015).

[33] A. Leemann, G.L. Saout, F. Winnefeld, D. Rentsch, and B. Lothenbach, "Alkali-silica reaction: the influence of calcium on silica dissolution and the formation of reaction products," J. Am. Ceram. Soc. 94 (4), 1243-1249 (2011).

[34] P.E. Grattan-Bellew, Discussion of paper "Alkali-aggregate reaction in concrete containing high-alkali cement and granite aggregate" by Z. Owsiak, Cem. Concr. Res. 35, 1868-1869 (2005).

[35] Z. Owsiak, Internal Corrosion of Concrete, Kielce University of Technology, Kielce, 2015.

[36] C. Fammy, K.L. Scrivener, A. Atkinson, and A.R. Brough, "Influence of the storage conditions on the dimensional changes of heat-cured mortars", Cem. Concr. Res. 31(5), 795-803 (2001).

[37] W. Kurdowski and H. Szeląg, "Concrete destruction caused by delayed ettringite formation", XXV Conference of Structural Failures, 1119-1126 (2011). 